the edge of the ligament and is firmly pushed through the tissues on to the forefinger of the left hand. In this manner the helix is made to travel along the ligament, care being

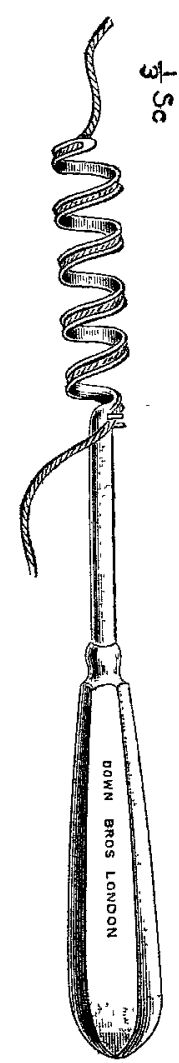
taken that whenever the point is being pushed through the tissues the left fore- finger ascertains that it has passed completely in through, otherwise there would be danger of the point passing between and not through the layers. The handle of the needle is then depressed so as to elevate the point and to bring it into position as much as possible. With an aneurysm needle the free end of the suture can easily be released from the tissues. The next step is the unthreading of the needle, and in order to facilitate this the groove is made to terminate half an inch from the eye, so that a pointed needle can easily take hold of the suture and draw it out of the eye. This was a suggestion made by Mr. Down and adds greatly to the value of the instrument. The end of the suture thus freed is held in a pair of clip forceps, while the helix is slowly withdrawn by rotating it in the opposite direction, leaving the suture in its track. By pulling the free ends the suture is tightened and the tissues embraced by the suture are completely strangled. A portion of ligament is now included in a continuous suture, leaving two free ends yet to be dealt with. The distal free end is threaded to an aneurysm needle and carried by it through the tissues, so that when unthreaded there is a loop and free end on the surface of the ligament; these are made into a firm knot. The suture is again tightened by pulling on the remaining free end. All that remains to complete the operation is to deal with the proximal free end in the same manner, except that the pedicle needle is first carried round the edge of the ligament.

F. W. Robinson, M.D. Aberd., F.R.C.S. Eng., Honorary Surgeon, Huddersfield Infirmary.

\section{A "SUTURE SICKLE."}

THE removal of sutures in some situations, and especially in cavities, is sometimes a matter of difficulty. To simplify the procedure I have devised an instru. ment in shape something like a short aneurysm needle on a long handle. The concave edge is, how. ever, sharp and the point is blunted like a small probe. It is an easy matter to pass the probe-point under a suture and to cut through with a slight jerk and only one hand is required. The sickle will be found a convenience for removing sutures from the uterine cervix, since the slender instrument in the speculum does not obscure the light and no forceps or scissors are required. I have also found it to simplify the removal of stitches in the perineum and on skin surfaces generally. Dr. C. Lawson Smith, resident medical officer at the Tottenham Hospital, has found it to answer well for general surgical cases. Messrs. Mayer and Meltzer, who make the instrument, have carried out my idea very satisfactorily.

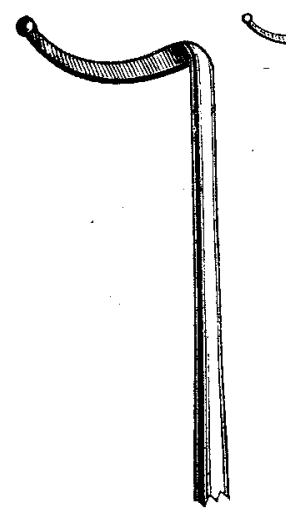

Arthur E. GiLes.

Upper Wimpole-street, $\mathrm{W}$.

\section{Iooking JBack.}

FROM

\section{THE LANCET, SATURDAY, JULY 17, 1824.}

The pre-disposing cause of scrofula is congenital, "t or original fault of constitution. The exciting causes are whatever tend to produce, or rather increase that debility; such as the fever from diseases of a specific kind, as measles, scarlet-fever, and small-pox. Scrofulous affections occurring after small-pox, used to be much more frequent before the introduction of vaccination than since, and if there were no other advantage attending it than this, it ought to be regarded as a boon to society. The reasons, you must be acquainted with, how small-pox disposes to the excitement of scrofulous inflammation, without my entering into them at present. ${ }^{1}$

We consider it our duty to censure improper practices wherever we find them; and we are really astonished to see the admission of persons into the wards of this hospital ${ }^{2}$ tolerated, who vend green gooseberries, unripe cherries and every other thing that a sick person should not have : tempting those to purchase who know no better and affording the opportunity to others, who from a vitiated appetite, regardless of the consequences, need no persuasion to do so. It should be recollected also, that there are many children in the wards who are always anxious to lay out the little money their friends may furnish them with in the first trash that is shown them. The result with them almost invariably is, a considerable irritation of the lining membrane of the stomach and bowels, and sometimes even amounting to inflammation with a corresponding constitutional disturbance; and we must not. suppose that even adults can escape with impunity. We have often observed great surprize manifested by the surgeon on finding the medicine which he had ordered produce just the opposite effect to that which was anticipated, which has induced him to substitute a less efficient remedy, under the supposition that the former one has disagreed with the patient. By which circumstance it happens that the patient is not only losing his time, but the surgeon is also losing confidence in the remedies he employs. We beg, therefore, to direct the attention of the proper authorities to this point, in order that it may be prevented for the future. We have before had occasion to notice this practice, and for a time it was discontinued. A repetition of the occurrence, has rendered a repetition of the caution necessary, and we hope that this gentle reminiscence. will not be without its effect.

1 Excerpt from a lecture delivered by Sir Astley Cooper in the Theatre of St. Thomas's Hospital on Monday evening, May 17th, 1824. Guy's.

London School of Medicine For Women.On July 11th, at 40, Hunter-street, W.C., the prizes won by the students of the London School of Medicine for Women were distributed by Mrs. Percy Sladen. The St. Dunstan scholarship given by the governors of the Endowed Charities of St. Dunstan's-in-the-East, value $£ 60$ a year for three years, was awarded to Miss Somner; the Singleton scholarship, value £95, to Miss Coupland; and the Mackay prizes of $£ 20$ each to Miss Bolton and Miss Payne. In referring to the work of the school during the past year Mrs. Garrett Anderson, dean of the school, who presided, remarked that financially they were still in debt with regard to the new building but they hoped in a short time to succeed in sweeping the debt away. During the year they had reduced the debt by $£ 1500$, and there was now left to be cleared off about $£ 6000$. The most important event of the year was the appointment by the Royal Free Hospital Committee of women to two of the resident posts at the hospital. These posts had been filled with conspicuous success. With regard to the South African Hospital Commission it was interesting to know that two of their past students, Miss Waterston and the Hon. Ella Scarlett, formed part of the commission and did exceedingly good and valuable work. 